\title{
Clinical correlation of ovarian mass with ultrasound findings and histopathology report
}

\section{Margaret Harriet Priya F.*, Vanusha, N. Hephzibah Kirubamani}

Department of Obstetrics and Gynecology, Saveetha Medical College and Hospital, Thandalam, Chennai, Tamil Nadu, India

Received: 27 September 2017

Accepted: 24 October 2017

\section{*Correspondence:}

Dr. Margaret Harriet Priya F.,

E-mail: margaretpriya10@gmail.com

Copyright: (c) the author(s), publisher and licensee Medip Academy. This is an open-access article distributed under the terms of the Creative Commons Attribution Non-Commercial License, which permits unrestricted non-commercial use, distribution, and reproduction in any medium, provided the original work is properly cited.

\section{ABSTRACT}

Background: As the ovarian malignancy is most common among genital malignancy, the diagnosis of malignant ovarian tumour helps us to plan the treatment modality like neoadjuvant chemotherapy, chemoradiation, radiotherapy, surgery and fertility sparing surgery depending upon stage of the disease and age of the patient. This study correlates between the clinical and ultrasound findings of ovarian tumours to diagnose the nature of the tumour whether benign or malignant and offer appropriate treatment and finally correlated with histopathology report. The aim of this study was to correlate clinical, USG morphology, colour doppler indices in ovarian mass with histopathology report.

Methods: This is a prospective observational study conducted at Saveetha Medical college and hospital between June 2016 to May 2017 for women who were clinically diagnosed to have ovarian mass and operated for it. These patients underwent trans vaginal (if married) or trans abdominal ultrasound and Doppler using GE S7 expert or Sonoline Acuson x300 (siemens) or Philips HD 11xE. Based on clinical findings and on the characterization of the image in USG and colour doppler findings it will be concluded whether the mass is benign or malignant. This is correlated with HPE report.

Results: Out of 113 women studied ovarian mass diagnosed clinically as benign in $78 \%$ and malignant in $21 \%$. USG prediction of ovarian cancer was $88.00 \%$ sensitivity, $80.68 \%$ specificity. When Doppler findings were included sensitivity was $91.43 \%$ and specificity was $91.03 \%$. The combined use of clinical and USG with Doppler for diagnosis of ovarian malignancy was $92.31 \%$ sensitive and $95.95 \%$ specific. The positive predictive value of combined use of clinical and USG with Doppler for diagnosis of ovarian malignancy was $92.31 \%$.

Conclusions: From this study clinical, USG and Doppler are important modalities in diagnosing benign or malignant ovarian tumour. When both are combined the diagnostic value is extremely high. This aids in planning the management.

Keywords: Doppler, Ovarian neoplasm, Pathology, Ultrasonography

\section{INTRODUCTION}

Adnexal masses are most common disease in gynaecology of which ovarian tumours represent $2 / 3^{\text {rd }}$ of these cases. ${ }^{1}$ This study is done to find out the diagnostic accuracy of clinical examination combined with ultrasonography and its correlation with histopathological diagnosis in ovarian mass. Ovarian tumours are usually diagnosed late only when they attain a bigger size. Small ovarian mass which are likely to be missed on physical examination pose a diagnostic challenge. They are identified easily when combined with pelvic ultrasound. Hence USG was used to classify ovarian tumour into benign and malignant by transvaginal ultrasound if 
married and transabdominal ultrasound if unmarried. Based on the clinical findings, ultrasound and Doppler findings, a preoperative accurate identification of the nature of the mass can be done before surgical intervention. However histopathological diagnosis of ovarian is the gold standard.

An accurate preoperative assessment of patient with ovarian mass is important to differentiate between benign and malignant lesions. Though there are limitations of pelvic examination in accurately identifying ovarian masses clinically, it can be differentiated as benign and malignant with the below findings. Benign ovarian mass will be unilateral, cystic, freely mobile, well defined borders without ascites. Malignant ovarian mass will be bilateral, firm to hard in consistency, ill-defined border, restricted mobility with ascites. The age specific incidence rate for ovarian cancer revealed that the disease increases from 35 years of age and reaches a peak between the ages 55 and $64 .^{2}$ Non-gynaecologic causes of an adnexal mass, such as inflammatory disease or neoplastic colonic mass or even a pelvic kidney can stimulate ovarian cancer. ${ }^{3}$ A preoperative suggestion of malignancy can guide the gynaecologist to refer women with suspected pelvic masses to a trained gynaecological oncologist for appropriate therapy and optimized debulking, which is known to improve survival. ${ }^{4}$ So the objective of the study is to know the accuracy of clinical combined with Ultrasound, Doppler in differentiating between benign and malignant ovarian masses.

\section{METHODS}

It is a prospective observational study conducted for one year from June 2016 to May 2017. Total number of 113 patients admitted in Gynecological ward of Saveetha Medical College and Hospital with ovarian masses and operated for it were enrolled in the study. Patients in whom ovarian mass was detected accidently during pelvic examination and USG and patients with symptoms like lower abdomen pain, palpable mass and menstrual irregularity with ovarian mass in USG was included in the study. Informed written consent was obtained after explaining in detail about the study protocol to all the patients.

A detailed menstrual, obstetric and medical history of each patient was taken. A detailed general, systemic and pelvic examination was done. USG and Doppler evaluation of all ovarian mass was done.

The mass was predicted as benign or malignant according to following criteria. The ovarian mass is considered malignant if it has an ill-defined border with ascites, with mural nodule, mixed echogenecity, multiloculated, with thick sepations and solid components. In Doppler malignant ovarian mass has increased vascularity and decreased resistance flow. The mass is considered benign if it is an unilocular cysts which is clear, with welldefined borders, homogenous echoes, thin septations and no ascites. If one or more malignant features were present in absence of benign feature, the mass is classified as malignant. If one or more benign feature is present in absence of malignant feature it is benign. If both are present or both are not present, it is in conclusive. After all necessary laboratory investigation and thorough evaluation all patients were subjected for surgery. Removal of uterus and the other ovary depends on the age and fertility requirement of the patient. The histopathology report is correlated with the USG findings for the patients operated for ovarian mass.

All the specimens were subjected to histopathological confirmations and they were correlated with preoperative clinical and USG findings. Analysis were performed using SPSS software, version 16.0. Sensitivity, specificity, negative and positive predictive value were calculated using medcalc software, for combined clinical, USG and doppler diagnosis and its correlation with histopathological diagnosis as the gold standard.

\section{RESULTS}

In the present study most of the patients with ovarian mass, almost $71 \%$ presented with pain abdomen and $1.77 \%$ were asymptomatic. Abdomen pain, bleeding per vaginum on and off were also the most common symptoms. Infertility due to ovarian mass was rare in the present study (Figure 1).

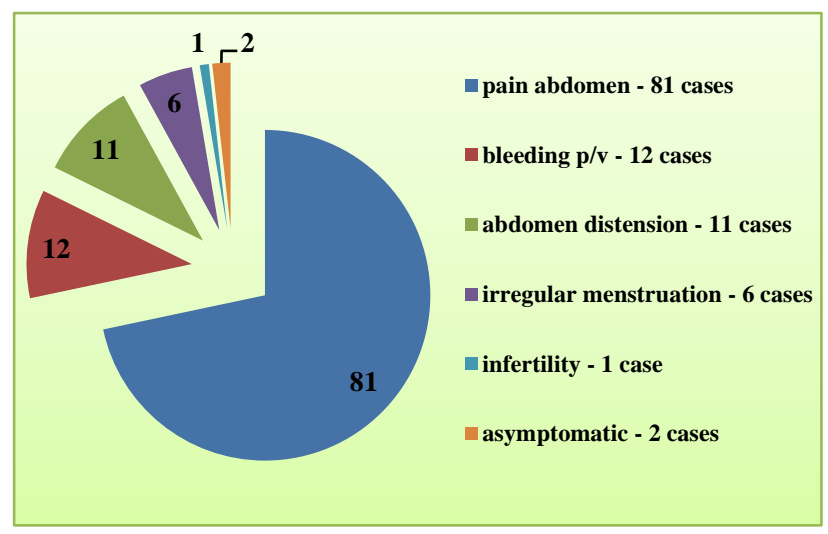

Figure 1: Symptoms of patients with ovarian mass.

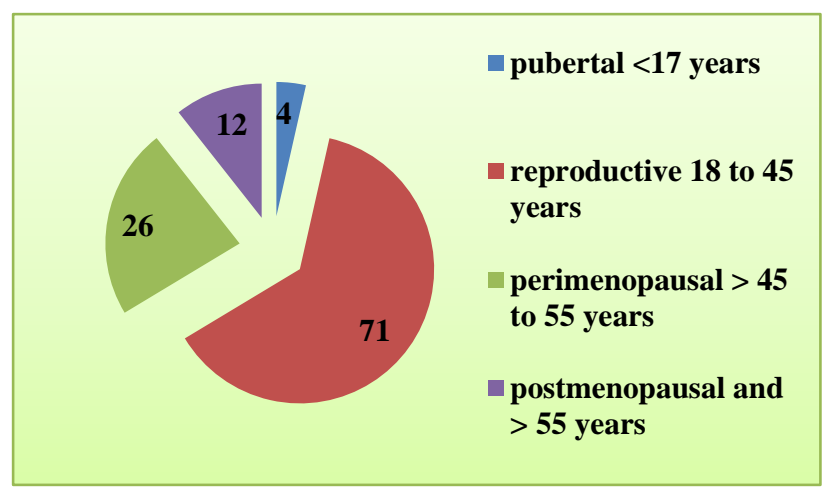

Figure 2: Age group distribution of ovarian mass. 
The age group distribution of patients in the present study ranged from 11 to 73 years with a mean age of 42 years. $62.83 \%$ of women were in reproductive age group and $10.62 \%$ in postmenopausal age group. About 4 cases were reported in pubertal age group and no cases in prepubertal period (Figure 2).

When clinical findings were correlated with HPE, 14 cases were true positive, and 72 cases were true negative (Table 1). Even though clinical examination plays a vital role in diagnosing ovarian tumours, most of them are missed due to obese abdomen. Hence USG helps us in diagnosing ovarian mass.

Table 1: Clinical with HPE correlation in diagnosing malignant ovarian tumour.

\begin{tabular}{|c|c|c|c|c|}
\hline \multirow{6}{*}{ Clinical } & \multicolumn{4}{|c|}{ Histopathology } \\
\hline & & Malignant & Benign & Total \\
\hline & Malignant & 14 & 25 & 39 \\
\hline & Benign & 2 & 72 & 74 \\
\hline & Total & 16 & 97 & 113 \\
\hline & $\mathrm{P}$ value $<$ & & & \\
\hline
\end{tabular}

Figure 3, 4 and 5 shows an USG picture of multilocular ovarian mass, its specimen picture and histopathology picture respectively, which was a seromucous carcinoma of ovary.

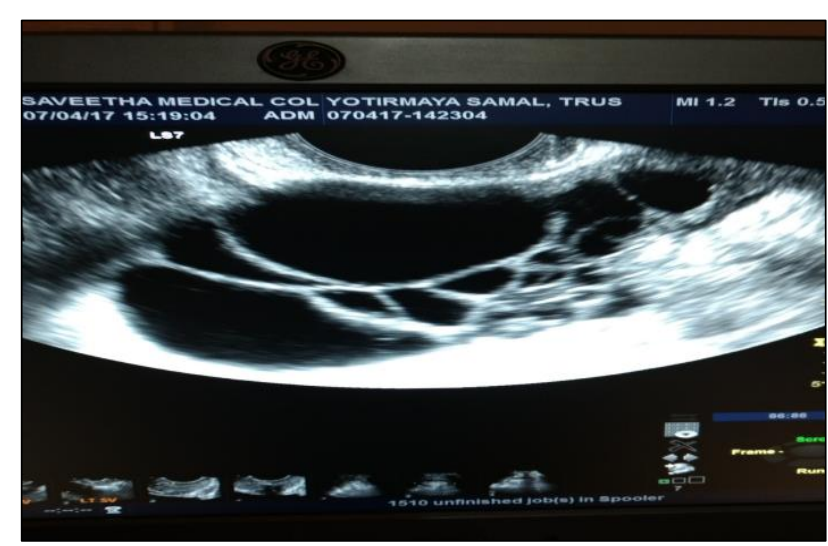

Figure 3: USG picture showing multilocular ovarian mass.

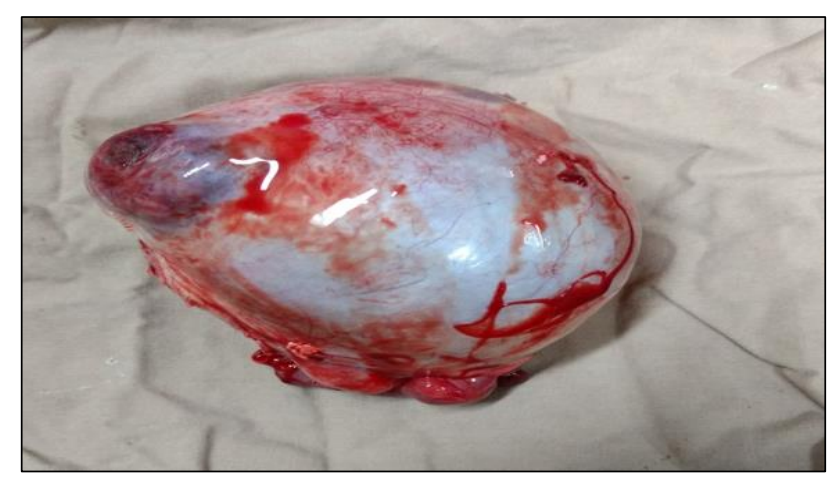

Figure 4: Specimen of multiloculated ovarian mass.

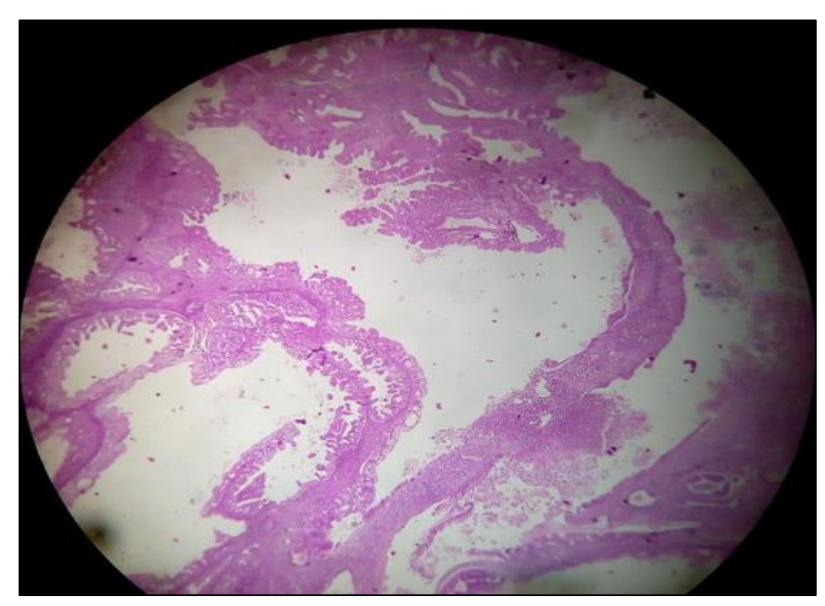

Figure 5: Histopathology of seromucinous carcinoma of ovary.

When USG features were correlated with HPE, 3 cases were false negative and 17 were false positive. While using USG false negative is high, which has been decreased when Doppler is combined with USG (Table 2).

Table 2: USG with HPE correlation in diagnosing malignant ovarian tumour.

\begin{tabular}{|c|c|c|c|c|}
\hline \multirow{6}{*}{ USG } & \multicolumn{4}{|c|}{ Histopathology } \\
\hline & & Malignant & Benign & Total \\
\hline & Malignant & 22 & 17 & 39 \\
\hline & Benign & 3 & 71 & 74 \\
\hline & Total & 25 & 88 & 113 \\
\hline & $\mathrm{P}$ value $<0$ & & & \\
\hline
\end{tabular}

In USG, 3 cases which was cystic turned to be malignant and 4 cases which had papillary projections were benign in HPE. When it had both solid and cystic components most of them were malignant, whereas purely solid ovarian masses were definitely malignant. All cases without papillary projections were benign (Table 3 ).

Table 3: USG features.

\begin{tabular}{|lll|}
\hline USG features & Benign: per/74 & Malignant: per/39 \\
\hline Cystic & 70 & 3 \\
\hline Solid-cystic & 4 & 33 \\
\hline Solid & 0 & 3 \\
\hline $\begin{array}{l}\text { Papillary } \\
\text { projections } \\
\text { present }\end{array}$ & 4 & 39 \\
\hline $\begin{array}{l}\text { Papillary } \\
\text { projections } \\
\text { absent }\end{array}$ & 70 & 0 \\
\hline
\end{tabular}

In Doppler, 8 cases with vascularity, 4 cases with RI $<0.4$ and 2 cases with PI $<1.0$ were benign in HPE. Whereas all malignant cases had vascularity, RI $<0.4$ and PI $<1.0$. (Table 4). 
Table 4: Doppler findings.

\begin{tabular}{|lll|}
\hline Doppler features & $\begin{array}{l}\text { Benign: } \\
\text { per } / 74\end{array}$ & $\begin{array}{l}\text { Malignant: } \\
\text { per } / 39\end{array}$ \\
\hline Vascularity present & $8 / 74$ & $39 / 39$ \\
\hline Vascularity absent & $66 / 74$ & $0 / 39$ \\
\hline RI $<0.4$ & $4 / 74$ & $39 / 39$ \\
\hline RI $>0.4$ & $70 / 74$ & $0 / 39$ \\
\hline PI $<1.0$ & $2 / 74$ & $39 / 39$ \\
\hline PI $>1.0$ & $72 / 74$ & $0 / 39$ \\
\hline
\end{tabular}

When Doppler features were compared with HPE report, 32 cases were true positive, and 71 cases were true negative. Doppler helps in overcoming false positive cases when combined with USG (Table 5).

When clinical features combined with USG and Doppler, compared with HPE, 36 cases were true positive, and 71 cases were true negative. So, all three diagnostic tools have a cumulative strategy in categorising the ovarian mass (Table 6).

When Clinical features, USG and Doppler were compared with HPE separately, sensitivity is more. When all the three parameters were combined and correlated with HPE, specificity is high. (Table 7).

Table 5: Doppler with HPE correlation in diagnosing malignant ovarian tumour.

\begin{tabular}{|c|c|c|c|c|}
\hline \multirow{6}{*}{ Doppler } & \multicolumn{4}{|c|}{ Histopathology } \\
\hline & & Malignant & Benign & Total \\
\hline & Malignant & 32 & 7 & 39 \\
\hline & Benign & 3 & 71 & 74 \\
\hline & Total & 35 & 78 & 113 \\
\hline & \multicolumn{4}{|c|}{$\mathrm{P}$ value $<0.0001$} \\
\hline
\end{tabular}

Table 6: Clinical + USG and Doppler with HPE correlation.

\begin{tabular}{lllll|} 
Clinical & \multicolumn{4}{c}{ Histopathology } \\
+ USG & & Malignant & Benign & Total \\
& Malignant & 36 & 3 & 39 \\
\cline { 2 - 5 } & Benign & 3 & 71 & 74 \\
\hline Total & 39 & 74 & 113 \\
& P value $<0.0001$ & &
\end{tabular}

Table 7: Screening characteristics of clinical examination, USG, Doppler and Clinical+USG with Doppler.

\begin{tabular}{|llllllll|}
$\begin{array}{l}\text { Screening } \\
\text { Characteristics }\end{array}$ & Sensitivity & Specificity & $\begin{array}{l}\text { Positive } \\
\text { predictive } \\
\text { value }\end{array}$ & $\begin{array}{l}\text { Negative } \\
\text { predictive } \\
\text { value }\end{array}$ & $\begin{array}{l}\text { Positive } \\
\text { likelihood } \\
\text { ratio }\end{array}$ & $\begin{array}{l}\text { Negative } \\
\text { likelihood } \\
\text { ratio }\end{array}$ & $\begin{array}{l}\text { Disease } \\
\text { prevalence }\end{array}$ \\
\hline Clinical & $87.50 \%$ & $74.23 \%$ & $35.90 \%$ & $97.30 \%$ & 3.40 & 0.17 & $14.16 \%$ \\
\hline USG & $88.00 \%$ & $80.68 \%$ & $56.41 \%$ & $95.95 \%$ & 4.56 & 0.15 & $22.12 \%$ \\
\hline $\begin{array}{l}\text { Doppler } \\
\begin{array}{l}\text { Clinical+USG } \\
\text { with Doppler }\end{array}\end{array}$ & $91.43 \%$ & $91.03 \%$ & $82.05 \%$ & $95.95 \%$ & 10.19 & 0.09 & $30.97 \%$ \\
\hline
\end{tabular}

\section{DISCUSSION}

Ovarian cancer among all gynecological cancers has worst prognosis because of lack of effective screening methods. $^{5}$ Preoperative prediction of benign and malignant nature of ovarian mass using available methods is necessary for proper management.

Among ovarian neoplasms $65.48 \%$ were benign and $34.51 \%$ were malignant. These findings are comparable with sharadha et al, Jha and Karki study. ${ }^{6,7}$ Mean age of malignant tumors was 42 years in our study which is similar to other studies done by wasim et al. ${ }^{8}$ A higher incidence of malignant ovarian tumors were found in postmenopausal women which is comparable to other studies. ${ }^{6,9}$ On other hand, benign ovarian tumors more often present in women of reproductive age group. Combination symptoms along with constitutional symptoms were present in all malignant patients which contradicts few other studies which report $7-15 \%$ of ovarian cancer patients are asymptomatic, when diagnosed. ${ }^{5,8}$ Clinical, bimanual examination has limited ability to discriminate benign from malignant masses which was proven in our study. Ultrasonography is a sensitive method for detecting ovarian cancer. For distinguishing benign and malignant adnexal mass, USG was used.

In the present study USG showed $88.00 \%$ sensitivity, $80.68 \%$ specificity in predicting ovarian cancer which is similar to studies done by Topez et al and Pourissa et al. ${ }^{9,10}$

In USG 3 cases turned to be malignant even though it was cystic in USG. 4 cases turned to be benign even though it had both cystic and solid components. 4 cases were benign with positive papillary projections, 8 cases were benign with vascularity, 4 cases were benign with RI <0.4, 2 cases were benign with PI $<1.0$ and 2 cases 
were malignant with PI $>1.0$ which is similar to the Khurana I et al study. ${ }^{11}$

The combined use of clinical and ultrasonography for diagnosis of malignancy in Radhamani et al study was $87.5 \%$ sensitive and $96.7 \%$ specific where as in the present study it is $92.31 \%$ sensitive and $95.95 \%$ specific. $^{12}$

Thus, according to the present results, use of combined clinical examination with USG and Doppler is strongly recommended to differentiate between benign and malignant ovarian tumors. Among histopathological types most common type of ovarian neoplasm in the present study was surface epithelial tumors (69\%) which is similar to other studies with $65 \%$ and $70 \%$ respectively. ${ }^{13,14}$

\section{CONCLUSION}

In this study the most common complaint due to ovarian mass was pain abdomen. Sensitivity and specificity in diagnosing the characteristics of ovarian tumour is good clinically, but diagnostic accuracy increased when USG along with Doppler is combined. Ovarian masses with entirely solid components, with papillary projections, with vascularity, RI $<0.4$ and PI $<1.0$ were definitely malignant. USG can be used even by a basic examiner to differentiate benign and malignant ovarian tumour which helps us in making decision regarding further management.

Funding: No funding sources Conflict of interest: None declared

Ethical approval: The study was approved by the Institutional Ethics Committee

\section{REFERENCES}

1. Hassan AY, Ellatif a AAA, Darweesh FF. Twodimensional ultrasound and doppler in assessment of adnexal masses in correlation to histopathological analysis. Academic J Cancer Res. 2014;7(1):8-18.

2. Murthy NS, Shalini S, Suman G, Pruthvish S, Mathew A. Changing trends in incidence of ovarian cancer - the Indian scenario. Asian Pac J Cancer Prev. 2009;10(6):1025-30.

3. Berek JS, Hacker NF. Practical Gynecologic Oncology, $3^{\text {rd }}$ ed. Philadelphia: Lippincott Williams and Wilkins. Quoted from Novak's Gynecology, $13^{\text {th }}$ Ed; 2000:3-33.
4. Junor EJ, Hole DJ, McNulty L, Mason M, Young J. Specialist gynaecologists and survival outcome in ovarian cancer: a Scottish national study of 1866 patients. Br J Obstet Gynaecol. 1999;106(11):11306.

5. Terzic MM, Dotlic J, Likic I, Ladjevic N, Brndusic $\mathrm{N}$, Arsenovic N, et al. Current diagnostic approach to patients with adnexal masses: which tools are relevant in routine praxis? Chin J Cancer Res. 2013;25(1):55-62.

6. Sharadha SO, Sridevi TA, Renukadevi TK, Gowri R, Binayak D, Indra V. Ovarian masses: changing clinico histopathological trends. J Obstet Gynaecol India. 2015;65(1):34-8.

7. Jha R, Karki S. Histological pattern of ovarian tumors and their age distribution. Nepal Med Coll J. 2008 Jun;10(2):81-5.

8. Wasim T, Majrroh A, Siddiq S. Comparison of clinical presentation of benign and malignant ovarian tumours. J Pak Med Assoc. 2009;59(1):18-21.

9. Topuz S, Saygili H, Akhan S, Yavuz E, Turfanda A, Berkman S. Differentiation of benign and malignant adnexal masses: value of a morphologic scoring system. Eur J Gynaecol Oncol. 2005;26(2):209-12.

10. Pourissa M, Refahi S, Moghangard F. The diagnostic accuracy of abdominal ultrasound imaging for detection of ovarian masses. Iran J Radiol. 2007;4(2).

11. Khurana I, Satia MN. Preoperative evaluation of ovarian masses with color Doppler and its correlation with pathological finding. Int $\mathbf{J}$ Reprod Contracept Obstet Gynecol. 2016;5(7):2084-92.

12. Radhamani S, Akhila MV. Evaluation of Adnexal masses - correlation of clinical, sonological and histopathological findings in adnexal masses. Int $\mathbf{J}$ Sci Stud. 2017;4(11):88-92.

13. Ahmad Z, Kayani N, Hasan SH, Muzaffar S, Gill MS. Histological pattern of ovarian neoplasma. J Pak Med Assoc. 2000;50(12):416-9.

14. Makwana HH, Maru AM, Lakum NR, Agnihotri AS, Trivedi NJ, Joshi JR. The relative frequency and histopathological pattern of ovarian masses: 11-year study at tertiary care centre. Int $\mathbf{J}$ Med Sci Public Health. 2014;3:81-4.

Cite this article as: Priya MHF, Vanusha, Kirubamani NH. Clinical correlation of ovarian mass with ultrasound findings and histopathology report. Int J Reprod Contracept Obstet Gynecol 2017;6:5230-4. 